\title{
PEDRO AZLOR, MÉDICO DE ISABEL LA CATÓLICA, Y SU PATENTE DE INVENCIÓN
}

\author{
Nicolás García Tapia \\ Catedrático de la Escuela Universitaria Politécnica de Valladolid. Departamento de Ingeniería \\ Energética y Fluidomecánica. C/ Francisco Mendizabal, 1 - 47014 Valladolid.
}

\section{RESUMEN}

Se presenta un privilegio por invención de molinos de 1478, registrado a nombre del médico de Isabel la Católica, Pedro Azlor, que, hasta el presente, es el primero conocido de los que se concedieron en España, en fechas inmediatas a las primeras patentes italianas, demostrando la rápida implantación en los reinos españoles de un sistema de protección al inventor característico del Renacimiento.

\section{SUMMARY}

In 1478, a privilege on the invention of mills was allowed to Pedro Azlor, a doctor of Queen Isabel la Católica. Up to now it has been the first one known in Spain. It was given inmediately after the first Italian patents, thus showing the quick settlement in the Spanish Kingdoms of a protection system for the inventor of the Renaissance period.

\section{INTRODUCCIÓN}

Los privilegios por invención, antecedentes de las actuales patentes, fueron iniciados en las repúblicas italianas de Florencia y Venecia en el siglo XV, extendiéndose en todo el mundo occidental a lo largo del XVI, como una forma de protección de los inventores. A pesar de ello, la inseguridad seguía siendo la tónica de los técni$\cos$, que veían a menudo copiadas sus creaciones y que preferían tomar otras precauciones para mantenerlas en secreto. Un caso muy conocido fue el de Leonardo da Vinci, ninguna de cuyas invenciones llegó a patentar, pero mantuvo a resguardo de la mirada de curiosos sus cuadernos de anotaciones.

En España, el inicio de las patentes de invención no había sido, hasta ahora, suficientemente investigado. La búsqueda de documentación sobre los primeros privilegios por invención nos ha conducido al descubrimiento de verdaderas patentes otor- 
gadas por el rey, bajo el dictamen de los Consejos Reales ${ }^{1}$. El primer privilegio por invención conocido y tramitado a través de la Cámara de Castilla data de 1522 y fue concedido a Guillén Cabier por una embarcación que, al parecer, se desplazaba sin necesidad de velas. Desde entonces, numerosas patentes fueron concedidas por los monarcas españoles a través de su Cámara y de sus Consejos, hasta las nuevas normas sobre patentes iniciadas en el siglo XVIII y culminadas con la creación de un Registro General de Patentes en el siglo XIX.

Anteriormente, en la época de los Reyes Católicos, los privilegios concedidos por éstos se depositaban en la sección de Registro General del Sello del Archivo Real de Simancas, por lo que hemos emprendido una búsqueda en esta sección para tratar de localizar los privilegios por invención de esta época. De esta forma hemos podido localizar lo que, hasta ahora, constituye el precedente más antiguo conocido de las patentes españolas, datado en 1478, pocos años después de las primeras patentes italianas.

\section{EL PRIVILEGIO DE INVENCIÓN DE PEDRO AZLOR}

El encabezamiento del documento en cuestión especifica que el privilegio se concede a Pedro Azlor, doctor en Medicina, del que más tarde se dice que era el "físico" de Isabel la Católica. Se trata de una licencia para "que pueda inventar y edificar en todas las partes del reino (se refiere a Castilla) molinos para moler pan y que ninquna persona edifique otros semejantes de aquí a veinte años, so ciertas penas". Está fechado en Sevilla, el 24 de febrero de 1478, siendo, en consecuencia, el primero de los que conocemos hasta ahora en España y uno de los más antiguos del mundo ${ }^{2}$.

Ya en el encabezamiento se indica que se trata de un privilegio por invención de nuevo tipo de molinos, expedido para que nadie pueda hacerlos de forma similar durante un periodo de veinte años, imponiendo ciertas penas a los infractores. Es decir, estamos ante un documento que contiene los elementos jurídicos básicos de una patente por invención.

La diferencia con los que se expedirán más adelante está en que este primer privilegio está concedido directamente por la reina Isabel de Castilla, sin que conste que hayan sido consultados los Consejos Reales, trámite que en posteriores patentes se hará imprescindible. Así, es la reina la que comunica a sus súbditos su decisión de

\footnotetext{
1 García TAPIA, N. (1990), Patentes de invención españolas en el Siglo de Oro, Oficina Española de Patentes y Marcas, Madrid.

2 Archivo General de Simancas, Registro General del Sello, 1478, fol. 26. Los párrafos que citamos, con ortografía actualizada, están tomados de este mismo documento, cuya transcripción paleográfica se ofrece en el apéndice.
} 


\section{PEDRO AZLOR, MEDICO DE ISABEL LA CATÓLICA, Y SU PATENTE DE INVENCIÓN}

otorgar el privilegio que el peticionario le había solicitado, y lo hace de la siguiente forma:

\footnotetext{
"Sepades que el doctor maestre Pedro Azlor, mi físico, me fizo relación que él quería inventar y facer en mis reinos y señoríos nuevos edificios y moliendas de facer pan..."
}

El hecho de que se trataba de un privilegio de nuevo tipo lo prueba el que se expliquen tan detalladamente los motivos por los que se concede, lo que no se hará en los documentos posteriores, seguramente porque se consideraba innecesario ya que éstos eran de sobra conocidos. Así se dice que:

\footnotetext{
"... redundará en qran provecho y utilidad de la cosa pública de mis reinos y senoríos, y que él (el inventor) se teme y recela que él, después de haber inventado y mostrado las dichas moliendas, que algunas personas, viendo su industria y orden que él en ello tiene, quieran hacer luego en ello otro tanto de la forma que él lo había hecho, siendo el primero que en estos mis reinos lo haya traído y creado".
}

Este revelador párrafo indica que los inventores veían frecuentemente copiadas y explotadas por otros sus invenciones, sin que ellos pudiesen evitarlo. Esto constituía un considerable perjuicio para el inventor que asistía impotente a la copia descarada de su creación, con la pérdida de los beneficios que su nueva invención podría haberle acarreado. Por otra parte, el inventor perdía, en este caso, todo el esfuerzo y la inversión que había hecho para imaginar y construir su invento, llevándose otros la fama y la gloria que correspondería al creador. Este sentimiento de ser dueño intransferible de su propia obra, es algo muy característico del Renacimiento, cuando los artistas empiezan a firmar su creación. Por este mismo motivo, se empieza a considerar al inventor como propietario intelectual de su obra técnica, con derecho a explotarla en exclusiva durante un periodo de tiempo.

Pero, al mismo tiempo, el párrafo anterior nos deja con la duda de si Azlor había hecho él mismo la invención o se había limitado a importar algo que ya se hacía fuera de España. Esto último parece indicarse cuando se dice que fue "el primero que en estos mis reinos lo haya traído y creado", aunque a veces lo de "traer" tenía el mismo significado que "inventar". Es difícil comprobar la originalidad de esta invención de molinos, ya que en ningún momento se revela en qué consistía. En todo caso, lo que se asegura es que era nuevo en los reinos españoles, lo cual era suficiente entonces para merecer una protección real.

Se insiste además en el coste y el esfuerzo que había hecho Pedro Azlor para conseguir el nuevo procedimiento de moler y los perjuicios económicos que le ocasionaría si otras personas le copiasen: 
Por todas estas razones, la reina Isabel tiene a bien acceder a la petición de su médico de poder realizar su nuevo método para moler, "así de agua, como de hombres, o fuerza de bestias o de viento". Es decir, Azlor había encontrado un nuevo sistema de molienda que podía funcionar en molinos de mano, de animales, hidráulicos y eólicos. En definitiva, en todas las posibilidades energéticas que entonces se conocían. Digamos, de paso, que este privilegio de invención prueba que los molinos de viento eran ya tan conocidos en Castilla en el siglo $\mathrm{XV}$, que podían ser incluso objeto de invenciones. Esto refuta, una vez más, la creencia general de que los molinos de viento se introdujeron en el interior de España en la época de Cervantes, limitados a algunas zonas de La Mancha. En realidad, los molinos de viento se conocían ya en Castilla la Vieja en la Edad Media ${ }^{3}$.

Otra cuestión es el tiempo por el que se concede el privilegio en exclusiva: "... hasta cumplidos veinte años primeros siguientes...". Este plazo variará en los sucesivos privilegios de invención que se darán a partir de entonces: en unos casos sólo serán por diez años, mientras que en otros se alargarán por "tres vidas", o tres generaciones de herederos. Pero el caso más frecuente será por veinte años, como en este privilegio.

Para hacer cumplir esta orden de la reina se establecen las correspondientes sanciones para los infractores: una compensación de veinte mil maravedís que será destinada a Pedro Azlor, además de treinta mil maravedís para la Cámara Real. Estas sanciones variarán en posteriores privilegios en función de la importancia y del coste estimado de la invención. Además de ello, el que copie la invención verá destruida su obra a su cargo. Todo esto será ejecutado por los jueces ante los cuales el inventor, o su representante, denuncie la copia.

Con este documento Pedro Azlor tenía garantizado, al menos en teoría, la seguridad de que su invención no podía ser copiada y de que podía explotarla en exclusiva durante veinte años. Desconocemos el uso que hizo el inventor de este privilegio y si sus nuevos molinos se pusieron en marcha. En todo caso, sabemos que la técnica molinar fue objeto de numerosas patentes en los años siguientes.

3 García Tapia, N. (1995), "La técnica en la Edad Media en Castilla", Santo Domingo de Caleruega. Contexto Cultural. III Jornadas de Estudios Medievales. Salamanca. 33-56, p. 52. 


\section{PEDRO AZLOR, MEDICO DE ISABEL LA CATÓLICA, Y SU PATENTE DE INVENCIÓN}

\section{UN MÉDICO INVENTOR DE MOLINOS}

Puede sorprender que un médico de la Corte se dedique en el siglo XV a inventar molinos, algo que, en principio, se creía que estaba reservado a los "mecánicos" que ejercían oficios considerados como indignos de una ocupación intelectual.

Pedro Azlor no fue el único médico que se dedicó a la invención de molinos. Señalaremos, como ejemplo, el caso del medinense Gómez Pereira, conocido sobre todo por una obra escrita en latín y publicada en 1554 en Medina del Campo, titulada Antoniana Margarita, que tuvo una enorme repercusión. Escribió además una obra médica, también en latín, editada en 1558, en la imprenta de Francisco del Canto, tío del inventor Francisco Lobato. La relación entre Pereira y Lobato se basa en que inventaron y probaron conjuntamente, aunque con poco éxito, un nuevo tipo de molino funcionando por el principio de sifón.

El licenciado Pereira, junto con Lobato, estaban preocupados por solucionar el problema de los obstáculos que las presas de las aceñas ponían a la navegación de los ríos españoles. Ambos idearon un molino que tomaba el agua por medio de un sifón, sin necesidad de construir un azud, por lo que el río podría ser navegable. Lo ensayaron, al principio infructuosamente, en el estanque de una huerta de Medina del Campo. Posiblemente, el médico Gómez Pereira consiguió posteriormente hacerlo funcionar, ya que, el 30 de junio de 1563, se le concedió una patente por diez años por la invención de "unos molinos que podian funcionar sin presas, en un patio, corral, o parte cubierta cualquiera, con una cuba o dos de aqua, cada una de 25 ó 30 moyos $^{\prime \prime 4}$. (Un moyo equivalía a unos 258 litros). En esta patente no figuraba el nombre de Francisco Lobato, a pesar de que había colaborado con Gómez Pereira en esta invención del molino de sifón.

\section{CONCLUSIÓN}

La intervención de médicos, filósofos y científicos en la invención de molinos, demuestra que a España habían llegado también las ideas propias del humanismo italiano, con una valoración nueva de la técnica. El humanista español Juan Luis Vives lo expresa muy claramente exhortando a los estudiosos que presten atención a los problemas técnicos, a "las artes y descubrimientos humanos en lo que toca y atañe a la alimentación. al vestido, a la vivienda: en esta tarea le ayudarán los tratadistas de agricultura y los que estudian la naturaleza y las propiedades de las hier-

\footnotetext{
4 García TAPIA, N. (1990), p. 46. Archivo General de Simancas, Cámara de Castilla, Libros de Cámara, n 141, fol. 246v.
} 


\section{NICOLÁS GARCÍA TAPIA}

bas y los animales y los que trataron de arquitectura... las artes de tracción animal en que andan mezclados el caballo, el mulo, el buey y toda suerte de vehículos..."5.

Entre "las artes y descubrimientos humanos en lo que toca y atañe a la alimentación" citados por Vives, está la técnica de la molienda. Es lógico que sea un médico el que se ocupe de estos aspectos que, aunque parezcan "mecánicos", son fundamentales en la alimentación y en la salud. Es en esta materia, en la que el médico de la reina, Pedro Azlor, hace descubrimientos que pide sean protegidos por medio de una patente, ya que desea ser reconocido como inventor y obtener en exclusiva el fruto de su trabajo.

Sin duda, la preocupación por la protección y el reconocimiento de los inventores es uno de los signos más evidentes de la llegada del Renacimiento a España.

5 RosSI, P. (1965), Los filósofos y las máquinas, Barcelona. 
PEDRO AZLOR, MEDICO DE ISABEL LA CATÓLICA, Y SU PATENTE DE INVENCIÓN

\begin{abstract}
APÉNDICE
Transcripción del privilegio de invención.

Archivo General de Simancas. Registro General del Sello. 1478 II, fol. 26

Maestre Pedro Azlor, doctor en meleçina.

Liçencia. Que pueda ynventar e edificar por todas las partes del Reyno molinos para moler pan e que ninguna persona edifique otros semejantes de aquí a veynte años so çiertas penas.
\end{abstract}

(Con otra letra) 24 de febrero 78

\title{
(Al pie del folio) Sevylla febrero 78
}

Doña Ysabel por la gracia de Dios Reyna de Castilla, de León, de Toledo, de Siçilia, de Portogal, de Galizia, de Sevylla, de Córdova, de Murçia, de Jahen, de los Algarves, de Algeziras, de Gibraltar, prinçesa de Aragón e Señora de Viscaya e de Molina.

A los ynfantes, duques, marqueses, condes, perlados, maestres de las hórdenes, priores, comendadores e subcomendadores, alcaydes de los castillos e casas fuertes e llanas e ricos omes e a los concejos e regidores, asystentes, alcaldes, corregidores, alguaziles, merinos, veynte e quatros, cavalleros, escuderos e oficiales e omes buenos asy de la muy leal çibdad de Sevilla, como de las otras çibdades, villas e logares de los mys Regnos e Señoríos e a qualesquier e otras personas mys vasallos e súbditos e naturales e a cada uno e a qualquier de vos ante quienes esta my carta fuere mostrada o el traslado della sygnado de escribano público. Salud e gracia:

Sepades que el doctor maestre Pedro Azlor, my físyco, me fizo relaçión que él quería ynventar e fazer en mis Reynos e Señoríos nuevos edificios de molinos e moliendas de moler pan, el qual dize que redundará en grand prouecho e utilidad de la cosa pública de mys reynos e señoríos, e que él se theme e reçela que él, después de aver ynventado e mostrado las dichas moliendas, que algunas personas veyendo su yndustria e horden que él en ello tiene, quieran fazer luego en ello otrotanto de la forma que él lo había fecho, siendo el primero que en estos mys reynos lo aya traydo e creado. E aviendo en ello e en lo yndustriar e ynventar gastado muchas costas de maravedís, confiando se aprovechar de su saber, e que sy otra persona le oviese de tomar su ynvençión, él perdería todo su trabajo e no podría sacar dello la costa que en ello pusiese. Lo qual, si así pasase, diz que reçibiría grande agravio e daño, pues ha trabajado e empleado su tiempo en lo edificar e ha de fazer gastos en ello, por cuya cabsa me suplicó e pidió por merçed sobre ello le proveyese mandando que dentro de çierto tiempo ninguno no fuese osado de fazer ni edificar moliendas segund e la manera que nuevamente él lo había edificado acerca de las dichas moliendas de moler pan, asy de agua como de ombres, o fuerza de bestias o de viento, en la manera que él nuevamente lo había ynventado, e suplicóme que yo sobrello le proueyese. E yo túvelo por bien, por que vos mando que desde el día que el dicho Pedro Azlor edificare o mostrare la forma de las dichas moliendas de su nueva manera, dende fasta complidos veynte años primeros siguientes, no consintades ni dedes logar que alguna ni algunas personas sean osadas de fazer ni fagan moliendas ni molinos de tal forma que el 


\section{NICOLÁS GARCÍA TAPIA}

dicho Pedro Azlor fiziere. E le dexedes e consyntades fazer e edificar en qualesquier logares ábiles de mys reynos e señoríos qualesquier molinos e moliendas que él quisyere fazer, tanto que no faga daño ni perjuyzio a otro alguno. E esto fecho, que en lo susodicho ni en parte dello no le pongades ni consyntades poner enbargo ni enbaraço alguno. E sy otras personas lo quisieren fazer, que vos los dichos juezes no gelo consyntades ni dedes logar a ello, mas gelo derrocades. E los veynte mill maravedís de pena para el dicho doctor, e en tal manera será derribado, que costa alguna no quede dello durante el dicho tiempo de los dichos veynte años desde el día que el dicho doctor Pedro Azlor començare a descubrir el arte de los edifiçios de las dichas moliendas o hedificar en guisa que pueda usar de los dichos artefiçios veynte años, como dicho es. E non fagades ende al, so pena de mi merçed e de treynta mill maravedis para la cámara. Dada en la muy noble e muy leal çibdad de Sevylla a veynte e quatro días del mes de febrero, año del nasçimiento de Nuestro Salvador Jesucristo de mill e quatroçientos e setenta e ocho años. Yo la Reyna la fize escribir por mandado... (Rubricado). 